\title{
A Layered Uranyl Coordination Polymer with UV Detection Sensitivity, Stability, and Reusability
}

\author{
CHEN Lei, CHEN Lanhua, ZHANG Yugang, XIE Jian, DIWU Juan
}

\begin{abstract}
(State Key Laboratory of Radiation Medicine and Protection, School for Radiological and Interdisciplinary Sciences (RAD-X), Collaborative Innovation Centre of Radiological Medicine of Jiangsu Higher Education Institutions, Soochow University, Suzhou 215123, China)
\end{abstract}

\begin{abstract}
The sensitive detection of UV light is critical in industrial production and for personal protection, and the aim of this research is to develop novel UV detection materials. The uranyl unit generally exhibits relatively high UV absorption efficiency and strong fluorescence intensity. Hence in this work, a uranyl coordination polymer compound $\left[(\mathrm{TEA})_{2}\left(\mathrm{UO}_{2}\right)_{5}(\mathrm{PhPC})_{6}\right](\mathrm{TEA}=$ tetraethylammonium ion, $\mathrm{PhPC}=(2$-carboxyethyl $)$ phenylphosphinic acid, denoted as UPhPC-1) was successfully synthesized via the hydrothermal method. The structural analysis of UPhPC-1 based on the single crystal XRD data elucidates that there are three crystallographically unique uranyl centers. Two uranyl units are in the pentagonal bipyramidal geometry, while the third one is in the tetragonal bipyramidal geometry. All three uranyl units are connected by the ligands to form infinite uranyl layers in the $[b c]$ plane, which are packed via hydrogen bonding networks and $\pi^{-} \pi$ interactions to yield the overall layered structure. The stability test results of UPhPC-1 demonstrate that the compound exhibits good thermal and hydrolytic stability with high radiation resistance. Moreover, results of the UV irradiation experiments show that the intrinsic luminescence of UPhPC-1 is highly sensitive to $365 \mathrm{~nm}$ UV irradiation with a low detection limit and a fast response rate. A negative correlation between the emission intensity and the UV irradiation dosage was then established. The electron paramagnetic resonance data analysis strongly supports the production of radicals in UPhPC-1 under UV radiation, which leads to the partial quenching of the uranyl fluorescence. Furthermore, the radicals in the quenched sample can be readily eliminated by heating, resulting in the recovery of the photoluminescence intensity of UPhPC-1. The current results suggest suitable application potential of UPhPC-1 in the field of quantitative UV detection.
\end{abstract}

Key words: uranyl coordination polymer; luminescence spectroscopy; UV detection; structural chemistry

For decades, ultraviolet radiation receives rapidly growing attention due to its indispensable role in industrial production, security and anti-counterfeiting, health care, and other related fields ${ }^{[1-4]}$. However, excessive ultraviolet radiation would cause irreversible damage to human, such as epidermal hyperplasia, DNA damage, and melanoma skin cancers ${ }^{[5-6]}$. Since UV light is invisible to the naked eyes, the development of UV light detection materials is essential for the purpose of protection and radiation control. Various types of semiconductor photodetectors have been fabricated and commercialized, including photodiodes detectors ${ }^{[7]}$, thermoelectric sensors $^{[8]}$, metal-semiconductor-metal detectors ${ }^{[9]}$, and Schottky barrier detectors ${ }^{[10]}$. However, those materials still face several disadvantages. For example, the defects of semiconductor materials could significantly affect their sensitivity and efficiency, therefore high production standards are required.

Compared with traditional semiconductors, luminescent methods show clear advantages in high sensitivity, fast response rate, and low cost ${ }^{[11]}$. Over the years, many luminescent materials have been developed for this pur-

Received date: 2020-03-17; Revised date: 2020-04-08

Foundation item: Science Challenge Project (TZ2016004); National Natural Science Foundation of China (21771133, 21790374, 21906113); Natural Science Foundation of Jiangsu Province (BK20190044); Priority Academic Program Development of Jiangsu Higher Education Institutions (PAPD)

Biography: CHEN Lei (1995-), female, Master candidate. E-mail: 20174220040@stu.suda.edu.cn 陈 否(1995-), 女, 硕士研究生. E-mail: 20174220040@stu.suda.edu.cn

Corresponding author: DIWU Juan, professor. E-mail: diwujuan@suda.edu.cn 第五娟, 教授. E-mail: diwujuan@suda.edu.cn 
pose, among which luminescent Coordination Polymers (CPs) or Metal Organic Frameworks (MOFs) have been widely investigated primarily due to their advantages of structure diversity and adjustable functionality that can be readily realized by various selections of organic linkers and metal nodes ${ }^{[12-19]}$. Lanthanide and transition metals are two major groups of elements utilized to build luminescent CPs or MOFs.

The $5 \mathrm{f}$ element uranium is an emerging element used as photosensitive and luminescent materials. The hexavalent uranium generally exists as the divalent linear dioxo unit of $\mathrm{UO}_{2}{ }^{2+}$. The photoluminescence property of the uranyl unit originates from the HOMO-LUMO transition of hybridized molecular orbitals, which is not Laporteforbidden, and hence the UV absorption efficiency and emission intensity of the uranyl often exceeds those of lanthanides ${ }^{[20-24]}$. Furthermore, owing to the participation of the uranyl $5 \mathrm{f} / 6 \mathrm{~d}$ orbitals in bonding, the uranyl luminescence intensity is extremely sensitive to the variation of its coordination environment, endowing uranium bearing materials with high detection sensitivity ${ }^{[25-31]}$. The ongoing research regarding uranyl-based UV detection systems, though limited, has demonstrated their great application potential. For example, a uranyl carboxylate coordination polymer has been reported for the first time to have excellent detection capability of X- or $\gamma$-ray and sensitive response to the UV light ${ }^{[32]}$. In this work, the luminescence of the uranyl unit is proposed to be quenched by the free radicals generated by the bond breaking of the carboxylate group under UV radiation. Then, Liu, et $a l^{[33]}$ reported that the presence of coordinated DMF units of uranyl phthalate layers would significantly lower down the UV detection limit, due to the interaction between the uranyl unit and the radicals generated on the DMF units by the UV light. The authors have prepared convenient UV-test strips using this material. Moreover, the insertion of highly photosensitive molecules such as phenanthroline between uranyl oxalate layers would further extend the detection limit to the $10^{-9} \mathrm{~J}$ level. The irradiation of this compound would result in the photo-exfoliation of the layered compound to monolayer nanosheet, which is an irreversible process ${ }^{[34]}$. Besides actinide carboxylate compounds, a number of actinide phosphonate compounds with high structural diversity have also been reported, by virtue of the strong metal binding affinities of the phosphonate ligands ${ }^{[35-39]}$. However, their UV detection properties have rarely been reported.

Here, a bifunctional ligand containing both phosphinate and carboxylate moieties was utilized and a luminescent uranyl layered compound [(TEA $\left.)_{2}\left(\mathrm{UO}_{2}\right)_{5}(\mathrm{PhPC})_{6}\right]$ (TEA $=$ tetraethylammonium ion, $\mathrm{PhPC}=(2$-carboxyethyl $)$ phenylphosphinic acid, denoted as UPhPC-1) was synthesized via the hydrothermal method. The structure of UPhPC-1 was revealed by single crystal XRD technique, showing that both phosphinate and carboxylate groups are coordinated to the uranyl ions. The experimental results demonstrate that UPhPC-1 not only shows good thermal stability, hydrolytic stability, and radiation resistance, but also exhibits a fast response rate of $365 \mathrm{~nm}$ UV radiation with a low detection limit of $3.9 \mu \mathrm{J}$. The relationship between the UV radiation dosage and the uranyl emission intensity was established and the fluorescence quenching mechanism is proposed to be a radical-induced quenching process. Further studies suggest that the radicals can be readily eliminated by heating, leading to the recovery of the photoluminescence intensity of UPhPC-1.

\section{Experimental}

\subsection{Materials and synthesis}

Materials (2-carboxyethyl)phenylphosphinic acid (98\%, Energy Chemical) and tetraethylammonium hydroxide $\left(25 \mathrm{wt} \%\right.$ solution in $\mathrm{H}_{2} \mathrm{O}$, J\&K Scientific) were used directly without further purification. While uranium compounds used in laboratories contain depleted uranium, standard procedures for handling radioactive materials should be followed.

Synthesis A mixture of $\mathrm{UO}_{2}\left(\mathrm{NO}_{3}\right)_{2} \cdot 6 \mathrm{H}_{2} \mathrm{O}(0.05 \mathrm{~g}$, $0.1 \mathrm{mmol}),(2$-carboxyethyl)phenylphosphinic acid $(0.04 \mathrm{~g}$, $0.2 \mathrm{mmol})$, tetraethylammonium hydroxide $(0.2 \mathrm{~mL})$, and $\mathrm{H}_{2} \mathrm{O}(2 \mathrm{~mL})$ was added into a $20 \mathrm{~mL}$ Teflon-lined stainless steel autoclave. The autoclave was sealed and heated to $220{ }^{\circ} \mathrm{C}$ for $3 \mathrm{~d}$, and then cooled to room temperature in $24 \mathrm{~h}$. Brown yellow crystals were isolated as UPhPC-1.

\subsection{Characterization}

X-ray crystallography Single crystal X-ray diffraction data acquisition was carried out on a Bruker D8-Venture diffractometer with a Turbo X-ray Source (Mo-K $\alpha$ radiation, $\lambda=0.071073 \mathrm{~nm}$ ) adopting the directdrive rotating anode technique and a CMOS detector at $298 \mathrm{~K}$. The data frames were collected using the program APEX3 and processed using SAINT routine in APEX3. The structure of UPhPC-1 was solved by direct methods and refined by the full-matrix least squares on $\mathrm{F}^{2}$ using the SHELXTL program.

Powder X-ray diffraction (PXRD) PXRD patterns were collected on a Bruker D8 Advance diffractometer at $40 \mathrm{kV}$ and $40 \mathrm{~mA}$ with $\mathrm{Cu} \mathrm{K} \alpha$ radiation $(\lambda=0.154056 \mathrm{~nm})$ and a Lynxeye one-dimensional detector from $5^{\circ}$ to $50^{\circ}$ with a step of $0.02^{\circ}$ in $2 \theta$.

Photoluminescence and UV-Vis absorption spectroscopy The crystals were placed on quartz slides and 
photoluminescence and UV-Vis absorption spectra were acquired after auto-set optimization by Craic Technologies microspectrophotometer. The photoluminescence spectra of the solid samples before and after X-ray irradiation were collected by Steady State \& Transient State Fluorescence Spectrofluorometer.

Fourier transform infrared (FT-IR) spectroscopy The FT-IR spectra of the solid samples before and after irradiation were recorded in the range of $4000-400 \mathrm{~cm}^{-1}$ with the Thermo Nicolet iS 50 spectrometer.

Thermogravimetric analysis (TG) TG analysis was carried out using a NETZSCH STA449F3 instrument in the temperature range from $30-900{ }^{\circ} \mathrm{C}$ under a nitrogen flow at a heating rate of $10 \mathrm{~K} / \mathrm{min}$ for the dried sample.

Elemental analysis Elemental analysis $(\mathrm{C}, \mathrm{H}$, and $\mathrm{N})$ was performed with a Vario EL CHNOS elemental analyzer.

Electron paramagnetic resonance (EPR) spectroscopy The EPR data of the pristine sample and samples irradiated for $90 \mathrm{~min}$ by UV light and $226 \mathrm{~s}$ by X-ray were recorded on a Bruker EMXplus 10/12 EPR spectrometer equipped with an Oxford Instruments EPR901 liquid helium continuous-flow cryostat fitted with a superhigh-Q cavity, respectively.

UV detection experiments UV detection studies were carried out and luminescence spectra were recorded at various exposure time under $365 \mathrm{~nm}$ light.

$\mathrm{X}$-ray irradiation experiments The experiments were carried out using a RS-2000 Pro Biological Irradiator equipped with $\mathrm{Cu} \mathrm{K \alpha}$ radiation at a dose rate of $26.5 \mathrm{~Gy} / \mathrm{min}$ and the samples were irradiated for $226 \mathrm{~s}$.

Hydrolytic stability measurements The hydrolytic stability evaluation of UPhPC-1 was performed by soaking the samples in $\mathrm{HNO}_{3} / \mathrm{NaOH}$ aqueous solutions in the $\mathrm{pH}$ range from 5 to 12 and shaking for $24 \mathrm{~h}$. The soaked samples were isolated and dried for PXRD pattern analysis.

\section{Results and discussion}

\subsection{Structural elucidation}

Single crystal X-ray diffraction analysis reveals that UPhPC-1 crystallizes in the centrosymmetric space group, $\mathrm{P} \overline{1}$. As shown in Fig. 1 and Table S1, the asymmetric unit consists of two and a half unique uranyl ions, three $\mathrm{PhPC}$ ligands, and one distinctive tetraethylammonium ion.

The U1 and U3 units are in the pentagonal bipyramidal geometry with axial $\mathrm{U}=\mathrm{O}$ bond distances ranging from 0.1781(5) to $0.1789(4) \mathrm{nm}$. The U2 unit sits at the inversion center and is in tetragonal bipyramidal geometry with the typical uranyl bond distance of $0.1777(4) \mathrm{nm}$. All equatorial-bonding oxygen atoms of three uranyl units are provided from the PhPC ligand with bond distances

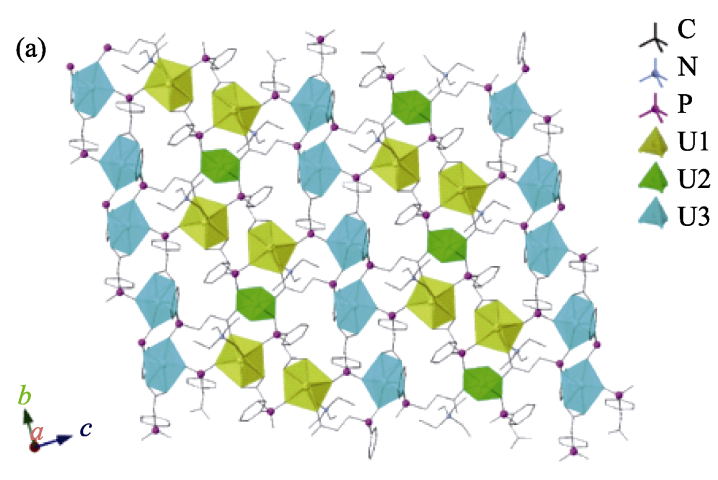

(b)

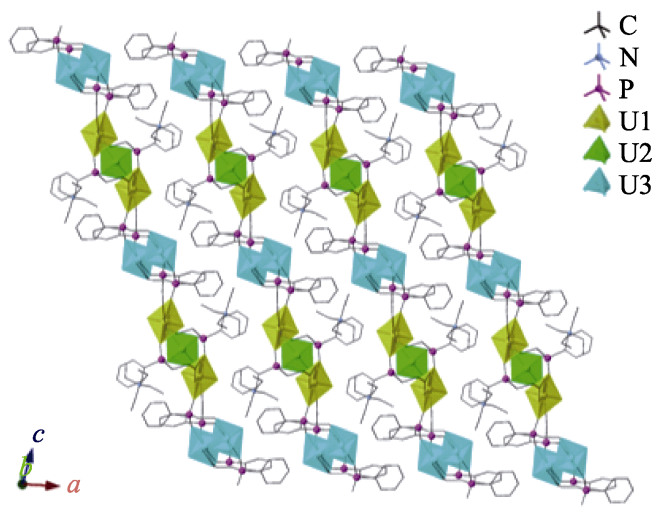

Fig. 1 Structural depiction of UPhPC-1

(a) View of the layer topology in the $[b c]$ plane; (b) View of the stacking mode of the uranyl layers

ranging from $0.2309(5)$ to $0.2491(4) \mathrm{nm}$. The bond valence sum values of the $\mathrm{U} 1, \mathrm{U} 2$, and $\mathrm{U} 3$ are calculated to be 6.019, 5.739, and 6.094, respectively. As shown in Fig. 1, all uranyl units are connected by the PhPC ligands to form the uranyl layers, which are packed via hydrogen bonding networks and $\pi^{-} \pi$ interactions to yield the overall layered structure. In the free space, there are tetraethylammonium cations to compensate the negative charge of the uranyl layers. The formula of UPhPC-1 is determined to be (TEA) $)_{2}\left(\mathrm{UO}_{2}\right)_{5}(\mathrm{PhPC})_{6}$ taken the results of single crystal structural analysis and elemental analysis (Table S2) into consideration. The FT-IR spectrum of UPhPC-1 was collected without $\mathrm{KBr}$ at room temperature. As shown in Fig. S1, the characteristic vibration peaks of the phenyl rings and the carboxylate units are identified between 1720 and $1250 \mathrm{~cm}^{-1[40-42]}$. The vibration peaks of the phosphinate groups are located in the range from 1200 and $950 \mathrm{~cm}^{-1}$. The peak at $\sim 920 \mathrm{~cm}^{-1}$ is assigned to the stretching vibration of the $\mathrm{O}=\mathrm{U}=\mathrm{O}$ unit $^{[43-44]}$.

\subsection{Irradiation dosage dependent luminescence spectra}

The photoluminescence spectrum of UPhPC-1 was collected under $365 \mathrm{~nm}$ excitation light at room temperature. As shown in Fig. S2, the spectrum of UPhPC-1 exhibits the characteristic emission peaks at 495, 516, 539,565 , and $592 \mathrm{~nm}$, corresponding to the $S_{10}-S_{0 v}(v=$ 
0-4) transitions of the uranyl unit. Compared with the emissive spectrum of $\mathrm{UO}_{2}\left(\mathrm{NO}_{3}\right)_{2} \cdot 6 \mathrm{H}_{2} \mathrm{O}$, the peak position of UPhPC-1 was red-shifted by $c a .7 \mathrm{~nm}$, probably caused by the coordination of the uranyl unit and the PhPC ligand, which is generally observed in uranyl coordination polymers ${ }^{[45-48]}$. The maximum UV-Vis absorption peak position of UPhPC-1 was also slightly shifted comparing to the reported data of $\mathrm{UO}_{2}\left(\mathrm{NO}_{3}\right)_{2} \cdot 6 \mathrm{H}_{2} \mathrm{O}$, as shown in Fig. S3.

To our surprise, the luminescent emission of UPhPC-1 was quenched rapidly after UV light irradiation, which could be observed by naked eyes. This phenomenon strongly suggests the potential of this material being used as a dosimeter for ultraviolet radiation. As shown in Fig. 2, the emission intensity of UPhPC-1 decreased significantly with the accumulative increase of the UV radiation dosage, indicating that the luminescence intensity of UPhPC-1 is responsive to the dosage of UV light not only instantly but also accumulatively. The emission peak intensity of UPhPC-1 was decreased by $79 \%$ after being exposed to $0.84 \mathrm{~mJ} 365 \mathrm{~nm}$ radiation and was almost completely quenched after $1.5 \mathrm{~h}$ exposure (Fig. 2(a)). To quantitively describe the negative correlation between luminescence intensity and UV radiation dosage, the quenching ratio of UPhPC-1 was calculated and expressed as $\left(I_{0}-I\right) / I_{0}$, where $I_{0}$ is the initial luminescence intensity and $I$ is the luminescence intensity after irradiation by ultraviolet light. The detection limit of UPhPC-1 can be determined by the following equations:
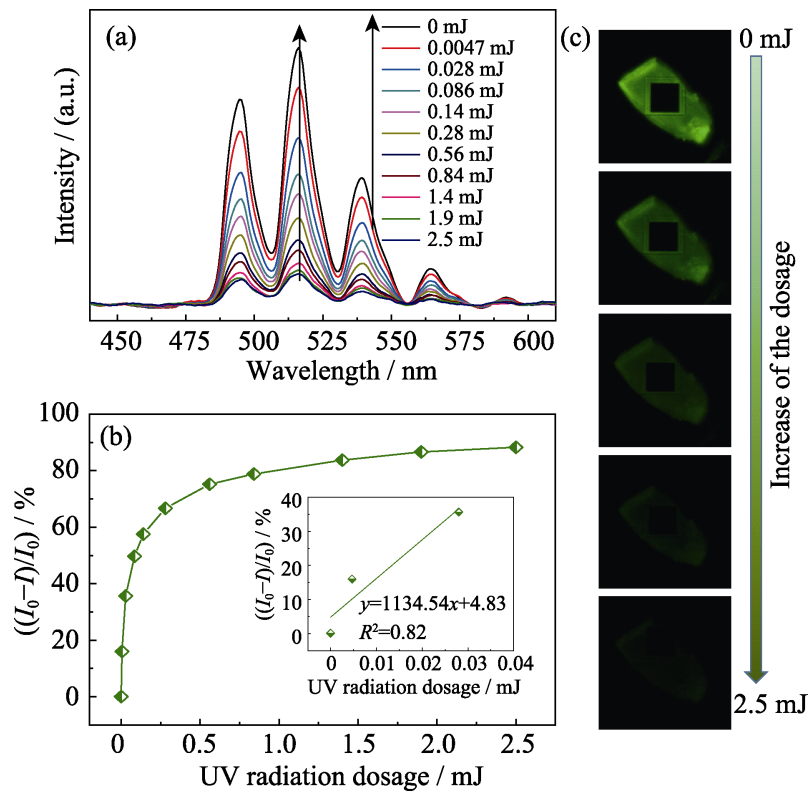

Fig. 2 Luminescence spectra (a) of UPhPC-1 with increasing doses of UV radiation, correlation between the quenching ratio and the UV radiation dose (b) (measured at $516 \mathrm{~nm}$ ), and corresponding photographs (c) of the single crystal under continuous UV irradiation

The inset is the linear fitting of the point data in the low dose range $(0-0.028 \mathrm{~mJ})$

$$
\begin{gathered}
D T=3 \sigma / k \\
\sigma=100 \times\left(I_{\mathrm{SE}} / I_{0}\right)
\end{gathered}
$$

Here $D T$ is the detection limit; $I_{\mathrm{SE}}$ is the standard error of the luminescence intensity; $I_{0}$ is the measured initial luminescence intensity of UPhPC-1; $k$ is the slope obtained from the linear fit in the low dosage range of the dosage-dependent luminescence intensity calibration curve.

The linear fitting can be achieved for the curve of the quenching ratio versus the dosage of UV irradiation in the low dose range (Fig. 2(b)). The detection limit of UPhPC-1 was determined to be $3.9 \mu \mathrm{J}$. Besides, the response rate of UPhPC-1 is faster than the uranyl-oxalate based UV detection material, demonstrating the high sensitivity of UPhPC-1 for the low dosage ultraviolet radiation. When exposed with 100 Gy X-ray, the luminescence intensity of UPhPC-1 was quenched by $66 \%$ (Fig. 3(a)).

\subsection{Stability evaluation}

The stability of UPhPC-1 was investigated in this work. The PXRD and FT-IR data show that the structural integrity of UPhPC-1 was maintained after UV light and $\mathrm{X}$-ray irradiation without any light-induced crystal degradation (Fig. S1 and Fig. S4). Those results demonstrate the high radiation resistance of UPhPC-1, which is comparable to other uranyl-based detection materials. The hydrolytic stability of UPhPC-1 was evaluated by soaking the crystalline samples in $\mathrm{HNO}_{3} / \mathrm{NaOH}$ aqueous solutions in the $\mathrm{pH}$ range from 5 to 12 and shaking for $24 \mathrm{~h}$. The experimental PXRD patterns of the soaked samples match well with the pattern of the pristine UPhPC-1 sample, indicating the excellent hydrolytic stability of UPhPC-1 (Fig. S4). Thermogravimetric analysis reveals that UPhPC-1 experienced several stages of weight loss in the temperature range from 30 to $900{ }^{\circ} \mathrm{C}$. As shown in Fig. S5, the first weight-loss of $1.72 \%$ before $380{ }^{\circ} \mathrm{C}$ is assigned to the loss of surface water molecules during the heating process. The loss of tetraethylammonium ion occurred at temperature above $400{ }^{\circ} \mathrm{C}$, resulting in the $10.7 \%$ loss in weight and the disruption of the overall structure. This decomposition temperature is higher than that of a previous reported two-dimensional uranyl-oxalate compound of $306{ }^{\circ} \mathrm{C}^{[32]}$.

\subsection{Quenching mechanism and reusability investigation}

The EPR analyses were performed on the irradiated and pristine crystalline samples to further investigate the fluorescence quenching mechanism (Fig. 3(b)). It was observed that the peak intensity of the irradiated samples increased significantly compared to the original sample, implying the generation of radicals, yet further theoretical 

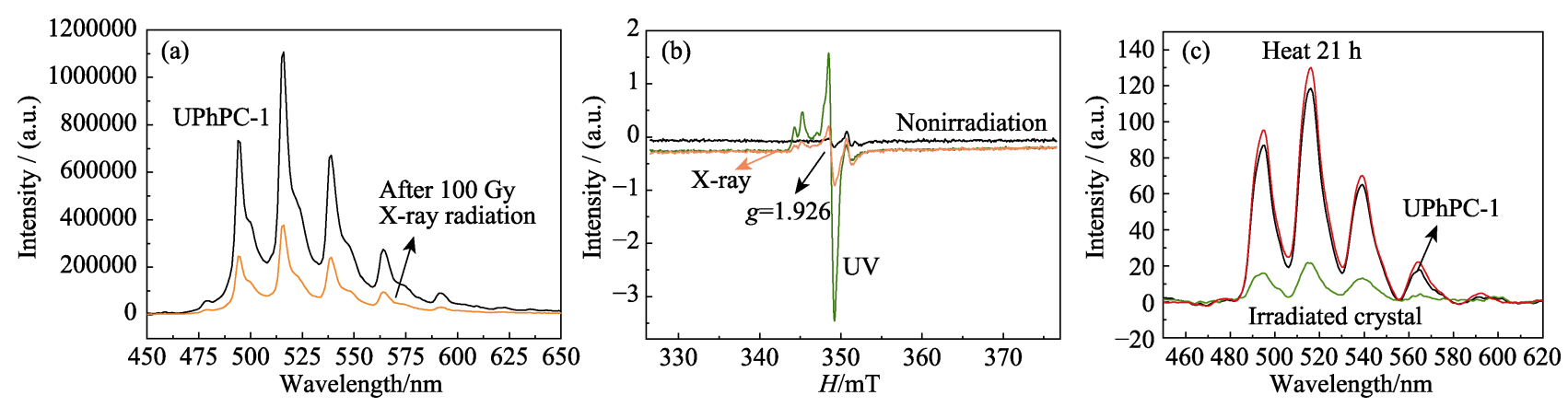

Fig. 3 Photoluminescence spectra (a) of UPhPC-1 before and after X-ray irradiation, EPR spectra (b) of UPhPC-1 before and after UV and X-ray irradiation, luminescence intensities (c) of UPhPC-1 before and after UV irradiation, and after the heating recovery process

calculation is necessary to identify those radicals. On the basis of the obtained data, we speculate that the most plausible quenching mechanism is the production of radicals possibly from the partial bond break of the ligand in the irradiated crystal, resulting in the energy transfer from the uranyl center to the nearby generated radicals, which leads to the quenching of the luminescence of $\mathrm{UPhPC}-1^{[33-34]}$.

The reusability of UV detection materials is also critical for their industrial development. Generally, it is not easy to obtain a reusable uranyl-based UV detection material since the recovery of the material requires not only the easy elimination of irradiation induced radicals, but also the ability to maintain the structural integrity during the irradiation and the recovery processes to restore its original photophysical properties. Generally, free radicals will not be able to stable for a long time, and heating accelerates the quenching process. The thermal elimination of radicals has been widely studied ever since 1970's and has already been applied in the industrial production ${ }^{[49-51]}$. Here in this work, we have demonstrated that the radicals in the quenched UPhPC-1 samples could be eliminated after heating at $150{ }^{\circ} \mathrm{C}$ for $21 \mathrm{~h}$. During the irradiation and heating process, the overall structure of UPhPC-1 is retained, and the uranyl fluorescence intensity could be fully restored (Fig. 3(c)). Therefore, the UPhPC-1 could be reused in a recovery way that is executable and cost-effective. A similar heating induced recovery was reported by $\mathrm{Xie}$, et $a l^{[33]}$.

\section{Conclusion}

In conclusion, we herein report a novel uranyl layered compound UPhPC-1 with high thermal and hydrolytic stability and radiation resistance. The intrinsic luminescence of UPhPC-1 was found to be highly sensitive to UV and 100 Gy X-ray irradiation, and a negative correlation between the emission intensity and the irradiation dosage was established with a low detection limit. The EPR data indicate that the production of free radicals after irradiation is responsible for the quenching of the uranyl emission. Therefore, we can reasonably conclude that UPhPC-1 exhibits suitable application potential in the field of quantitative UV radiation detection and provides a new application platform for a large inventory of depleted uranium.

\section{Supporting Materials}

Supporting materials related to this article can be found at https://doi.org/10.15541/jim20200139.

\section{References:}

[1] GINER TORRES S, MONTANES N, FENOLLAR O, et al. Development and optimization of renewable vinyl plastisol/wood flour composites exposed to ultraviolet radiation. Mater. Design, 2016, 108: 648-658.

[2] YUE WU, HE RIAN, YAO PING-JIA, et al. Ultraviolet radiationinduced accelerated degradation of chitosan by ozone treatment. Carbohyd. Polym., 2009, 77(3): 639-642.

[3] Westerhof W, NiEUWEbOeR KROBOtova L. Treatment of vitiligo with UV-B radiation $v$ s topical psoralen plus UV-A. Arch. Dermatol., 1997, 133(12): 1525-1528.

[4] NERANDZIC M MICHELLE, CADNUM L JENNIFER, PULTZ $\mathrm{J}$ MICHAEL, et al. Evaluation of an automated ultraviolet radiation device for decontamination of clostridium difficile and other healthcare-associated pathogens in hospital rooms. BMC Infect. Dis., 2010, 10: 197.

[5] NARAYANAN L DEEVYA, SALADI N RAO, FOX L J, et al. Ultraviolet radiation and skin cancer. Int. J. Dermatol., 2010, 49(9): 978-986.

[6] MANCEBO E SILVIA, WANG Q STEVEN. Skin cancer: role of ultraviolet radiation in carcinogenesis. Rev. Environ. Health, 2014, 29(3): 265-273.

[7] SCHOLZE F, KLEIN R, MULLER R. Characterization of detectors for extreme UV radiation. Metrologia., 2006, 43: S6-S10.

[8] FRITZ G GILBERT, WOOD S KENT, VECHTEN VAN DEBORAH, et al. Thermoelectric single-photon detectors for $\mathrm{X}$-ray/UV radiation. X-Ray and Gamma-Ray Instrumentation for Astronomy XI. International Society for Optics and Photonics, 2000, 4140: 459-469.

[9] HE CHENG, WU XIAO, KONG JI-CHUAN, et al. A hexanuclear gadolinium-organic octahedron as a sensitive MRI contrast agent for selectively imaging glucosamine in aqueous media. Chem. 
Commun., 2012, 48: 9290-9292.

[10] MONROY E, VIGUÉ F, CALLE F, et al. Time response analysis of ZnSe-based Schottky barrier photodetectors. Appl. Phys. Lett., 2000, 77: 2761-2763.

[11] FABBRIZZI LUIGI, LICCHELLI MAURIZIO, RABAIOLI GIULIANO, et al. The design of luminescent sensors for anions and ionisable analytes. Coordin. Chem. Rev., 2000, 205(1): 85-108.

[12] INUKAI M, TAMURA M, HORIKE S, et al. Storage of $\mathrm{CO}_{2}$ into porous coordination polymer controlled by molecular rotor dynamics. Angew. Chem. Int. Ed., 2018, 57(28): 8687-8690.

[13] DU YA, YANG HAI-SHEN, WAN SHUN, et al. A titanium-based porous coordination polymer as a catalyst for chemical fixation of $\mathrm{CO}_{2}$. J. Mater. Chem. A, 2017, 5(19): 9163-9168.

[14] CUI JING-WANG, HOU SUO-XIA, LI YUE-HUA, et al. A multifunctional $\mathrm{Ni}$ (II) coordination polymer: synthesis, crystal structure and applications as a luminescent sensor, electrochemical probe, and photocatalyst. Dalton Trans., 2017, 46(48): 16911-16924.

[15] NOVIO F, SIMMCHEN J, VÁZQUEZ-MERA N, et al. Coordination polymer nanoparticles in medicine. Coord. Chem. Rev., 2013, 257(19/20): 2839-2847.

[16] LI HAI-YANG, XU HONG, ZANG SHUANG-QUAN, et al. A viologen-functionalized chiral Eu-MOF as a platform for multifunctional switchable material. Chem. Commun., 2016, 52(3): 525-528.

[17] HU SHU-ZHI, ZHANG JIE, CHEN SHU-HUANG, et al. Efficient ultraviolet light detector based on a crystalline viologen-based metal-organic framework with rapid visible color change under irradiation. ACS Appl. Mater. Inter, 2017, 9(46): 39926-39929.

[18] ZHANG YING-MU, YUAN SHUAI, DAY GREGORY, et al. Luminescent sensors based on metal-organic frameworks. Coord. Chem. Rev., 2018, 354: 28-45.

[19] WANG YA-XING, YIN XUE-MIAO, WANG SHU-AO, et al. Emergence of uranium as a distinct metal center for building intrinsic X-ray scintillators. Angew. Chem. Int. Ed., 2018, 57(26): 7883-7887.

[20] PARKER DAVID, DICKINS S RACHEL, PUSCHMANN HORST, et al. Being excited by lanthanide coordination complexes: aqua species, chirality, excited-state chemistry, and exchange dynamics. Chem. Rev., 2002, 102(6): 1977-2010.

[21] LI FEI-ZE, MEI LEI, SHI WEI-QUN, et al. Uranyl compounds involving a weakly bonded pseudorotaxane linker: combined effect of $\mathrm{pH}$ and competing ligands on uranyl coordination and speciation. Inorg. Chem., 2019, 58(5): 3271-3282.

[22] ZHAO RAN, MEI LEI, SHI WEI-QUN, et al. Bimetallic uranyl organic frameworks supported by transition-metal-ion-based metalloligand motifs: synthesis, structure diversity, and luminescence properties. Inorg. Chem., 2018, 57(10): 6084-6094.

[23] MEI LEI, WU QUN-YAN, SHI WEI-QUN, et al. Silver ion-mediated heterometallic three-fold interpenetrating uranyl-organic framework. Inorg. Chem., 2015, 54(22): 10934-10945.

[24] LIU WEI, SONG EN-HAI, WANG SHU-AO, et al. Introducing uranium as the activator toward highly stable narrow-band green emitters with near-unity quantum efficiency. Chem. Mater, 2019, 31: 9684-9690.

[25] WU XU-MENG, WANG HONG-QING, WANG XIANG-KE, et al. Sensors for determination of uranium: a review. Trends in Analytical Chemistry, 2019, 118: 89-111.

[26] GUI DA-XIANG, DUAN WAN-CHUN, WANG SHU-AO, et al. Persistent superprotonic conductivity in the order of $10^{-1} \mathrm{~S} \cdot \mathrm{cm}^{-1}$ achieved through thermally induced structural transformation of a uranyl coordination polymer. CCS Chem., 2019, 1(2): 197-206.

[27] LI JIE, WANG XIANG-YUE, WANG XIANG-KE, et al. Metal-organic framework-based materials: superior adsorbents for the capture of toxic and radioactive metal ions. Chem. Soc. Rev., 2018, 47(7): 2322-2356.

[28] WANG LIN, LI ZIJIE, SHI WEI-QUN, et al. Layered structurebased materials: challenges and opportunities for radionuclide sequestration. Environ. Sci.: Nano, 2020, 7(3): 724-752.

[29] WANG XIANG-XUE, SHI WEI-QUN, WANG XIANG-KE, et al. Synthesis of novel nanomaterials and their application in efficient removal of radionuclides. SCI. China Chem., 2019, 62(8): 933-967.

[30] YIN XUE-MIAO, WANG YA-XING, WANG SHU-AO, et al. Competing crystallization between lanthanide and actinide in acidic solution leading to their efficient separation. Chin. J. Chem., 2019, 37(1): 53-57.

[31] WANG YAN-LONG, LIU ZHI-YONG, WANG SHU-AO, et al. Umbellate distortions of the uranyl coordination environment result in a stable and porous polycatenated framework that can effectively remove cesium from aqueous solutions. J. Am. Chem. Soc., 2015, 137(19): 6144-6147.

[32] XIE JIAN, WANG YA-XING, LIU WEI, et al. Highly sensitive detection of ionizing radiations by a photoluminescent uranyl organic framework. Angew. Chem. Int. Ed., 2017, 56(26): 7500-7504.

[33] LIU WEI, DAI XING, XIE JIAN, et al. Highly sensitive detection of UV radiation using a uranium coordination polymer. ACS Appl. Mater. Inter, 2018, 10(5): 4844-4850.

[34] XIE JIAN, WANG YA-XING, WANG SHU-AO, et al. Photoexfoliation of a highly photo-responsive two-dimensional metalorganic framework. Chem. Commun., 2019, 55(78): 11715-11718.

[35] ZHENG TAO, YANG ZAI-XING, GUI DA-XIANG, et al. Overcoming the crystallization and designability issues in the ultrastable zirconium phosphonate framework system. Nat. Commun., 2017, 8(1): 15369 .

[36] GUI DA-XIANG, ZHENG TAO, CHEN LAN-HUA, et al. Hydrolytically stable nanoporous thorium mixed phosphite and pyrophosphate framework generated from redox-active ionothermal reactions. Inorg. Chem., 2016, 55(8): 3721-3723.

[37] TIAN TAO, YANG WEI-TING, SUN ZHONG-MING, et al. Syntheses and structures of uranyl ethylenediphosphonates: from layers to elliptical nanochannels. Inorg. Chem., 2013, 52(12): 7100-7106.

[38] YANG WEI-TING, TIAN WAN-GUO, SUN ZHONG-MING, et al. Syntheses, structures, luminescence, and photocatalytic properties of a series of uranyl coordination polymers. Cryst. Growth Des., 2014, 14(11): 5904-5911.

[39] YANG WEI-TING, PARKER GANNON T, SUN ZHONG-MING. Structural chemistry of uranium phosphonates. Coord. Chem. Rev., 2015, 303: 86-109.

[40] LAN WEN-TING, HE LI, LIU YAO-WEN. Preparation and properties of sodium carboxymethyl cellulose/sodium alginate/chitosan composite film. Coatings, 2018, 8(8): 291.

[41] LAWRIE GWEN, KEEN IMELDA, DREW BARRY, et al. Interactions between alginate and chitosan biopolymers characterized using FTIR and XPS. Biomacromolecules, 2007, 8(8): 2533-2541.

[42] POLJANŠEK IDA, KRAJNC MATJAŽ. Characterization of phenolformaldehyde prepolymer resins by in line FT-IR spectroscopy. Acta. Chim. Slov., 2005, 52: 238-244.

[43] WANG YA-XING, LIU XIN, WANG SHU-AO, et al. Direct radiation detection by a semiconductive metal-organic framework. $J$. Am. Chem. Soc., 2019, 141(20): 8030-8034.

[44] COZACIUC ANDREEA IRINA, POSTOLACHI RODICA, GRADINARU ROBERT, et al. Synthesis and characterization of uranyl (VI) chiral Schiff-base complexes derived from salicylaldehyde and $L$-aminoacids. J. Coord. Chem., 2012, 65(12): 2170-2181.

[45] YANG WEI-TING, WANG HAO, SUN ZHONG-MING, et al. 
The first family of actinide carboxyphosphinates: two and threedimensional uranyl coordination polymers. Eur. J. Inorg. Chem., 2014, 2014(31): 5378-5384.

[46] YANG WEI-TING, WU DAI, SUN ZHONG-MING, et al. Structural variations of the first family of heterometallic uranyl carboxyphosphinate assemblies by synergy between carboxyphosphinate and imidazole ligands. Cryst. Growth Des., 2016, 16(4): 2011-2018.

[47] YANG WEI-TING, WANG HAO, SUN ZHONG-MING, et al. Isolation of a series of uranium organophosphinates. Cryst. Eng. Comm., 2014, 16(34): 8073-8080.

[48] ZHANG YU-GANG, CHEN LAN-HUA, GUAN JING-WEN, et al. A unique uranyl framework containing uranyl pentamers as secon- dary building units: synthesis, structure, and spectroscopic properties. Dalton Trans., 2020, 49: 3676-3679.

[49] RSTENSEN PETERCA. Free radicals in diene polymers induced by ultraviolet irradiation. II. an ESR study of cis-1.4-poly(butadiene). Die Makromolekulare Chemie: Macromol. Chem. and Phys., 1971, 142(1): 131-144.

[50] ZHANG XIAN, WANG SHENG-MING, SUN CAI, et al. Stabilizing and color tuning pyrazine radicals by coordination for photochromism. Chem. Commun., 2016, 52(51): 7947-7949.

[51] WANG SHENG-MING, XU GANG, ZHANG ZHANGJ-ING, et al. Inorganic-organic hybrid photochromic materials. Chem. Commun., 2010, 46(3): 361-376.

\title{
具有 UV 探测灵敏性、稳定性和重复 利用性的层状铀酰配位聚合物研究
}

\author{
陈 磊，陈兰花，张瑜港，谢健，第五娟
}

(苏州大学 江苏省高等学校放射医学协同创新中心, 放射医学及交叉科学研究院(RAD-X), 放射医学与辐射防护国 家重点实验室, 苏州 215123)

摘 要: 灵敏的 UV 探测对于工业生产和个人防护非常重要, 本研究旨在开发新型 UV 探测材料。一般而言, 铀酰单元 具有相对高的 UV 吸收效率和苂光强度。本课题组成功地在水热条件下制备了一例铀酰配位聚合物 $\left[(\mathrm{TEA})_{2}\left(\mathrm{UO}_{2}\right)_{5}(\mathrm{PhPC})_{6}\right](\mathrm{TEA}=$ 四乙基胺离子, $\mathrm{PhPC}=(2$-羧基乙基 $)$ 苯膦酸, 标记为 $\mathrm{UPhPC}-1)$ 。基于单晶 $\mathrm{XRD}$ 数据的 结构分析表明 UPhPC-1 中有三个不同的铀酰中心, 其中两个铀酰单元为五角双雉构型, 而第三个铀酰单元为四角双 锥构型。全部三个铀酰中心与配体在 $[b c]$ 平面配位形成无限的铀酰层。通过氢键网格和 $\pi-\pi$ 相互作用, 这些铀酰层堆 积成整体的层状结构。此化合物具有很好的热稳定性、水稳定性和高抗辐照能力。UV 辐照实验结果表明 UPhPC-1 的本征荧光强度对 $365 \mathrm{~nm}$ 的 UV 辐射高度敏感, 检测下限低且响应速率快, 而发光强度与 UV 辐照剂量呈负相关。 电子顺磁共振谱分析证实在 UV 光照射下, UPhPC-1 中极有可能产生自由基, 造成铀酰苂光部分淬灭。进一步, 被淬 灭样品中的自由基能够在加热后被去除, 从而实现 UPhPC-1 发光强度的快捷恢复。目前的结果表明 UPhPC-1 在 UV 辐照的定量探测领域具有一定的发展潜力。

关 键 词: 铀酰配位化合物; 荧光光谱; UV 探测; 结构化学

中图分类号: TQ174 文献标识码: A 